Rev. Ter. Ocup. Univ. São Paulo, v. 18, n. 2, p. 54-62, maio/ago., 2007.

\title{
Redes sociais e construção de projetos terapêuticos: um estudo em serviço substitutivo em saúde mental
}

\author{
Social networks and the construction of therapeutic \\ projects: a study in a mental health substitutive service
}

\author{
Elisabete Ferreira Mângia ${ }^{1}$, Melissa Muramoto ${ }^{2}$
}

MÂNGIA, E. F.; MURAMOTO, M. Redes sociais e construção de projetos terapêuticos: um estudo em serviço substitutivo em saúde mental. Rev. Ter. Ocup. Univ. São Paulo, v. 18, n. 2, p. 54-62, maio/ago., 2007.

\begin{abstract}
RESUMO: Estudos demonstram que pessoas com transtornos mentais severos que dispõem de rede social apresentam maior probabilidade de êxitos positivos em breves ou curtos períodos, nas áreas clínica, laborativa e relacional, tais resultados devem orientar a elaboração e realização das intervenções assistenciais e de reabilitação psicossocial desenvolvidas pelos serviços de saúde mental, de forma a priorizar a intervenção sobre a rede social. Nessa perspectiva, apresentamos resultados parciais da pesquisa de mestrado "A sustentabilidade da vida cotidiana. Um estudo das redes sociais de usuários de um serviço de saúde mental no município de Santo André", iniciada em 2005, que tem como objetivo geral caracterizar as redes sociais de pessoas com transtornos mentais severos, usuários de serviços substitutivos de saúde mental e identificar fatores que contribuam para a formulação de estratégias de ativação de redes. A pesquisa se inscreve no campo da investigação qualitativa e utiliza procedimentos orientados pela etnometodologia. Foram realizadas 25 entrevistas com usuários que recebiam atenção em regime de tratamento intensivo, pesquisa bibliográfica e observação participante, com a elaboração de caderno de campo. A análise preliminar dos dados possibilitou: a caracterização das redes sociais de usuários do serviço de saúde mental e de suas necessidades, além de confirmar a importância das redes sociais no percurso assistencial. Para o modelo assistencial, a validação de estratégias de ativação de redes sociais exige mudanças nas culturas técnica e de organização de serviços, e a definição de novos desenhos assistenciais, mais complexos e que incorporem em suas estratégias o manejo dos fatores de proteção, que garantem aos sujeitos a possibilidades de viver a vida fora dos circuitos de institucionalização.
\end{abstract}

DESCRITORES: Transtornos mentais. Reabilitação. Serviços de saúde mental. Institucionalização. Terapia ocupacional.

\footnotetext{
${ }^{1}$ Prof. Dra. do Departamento de Fisioterapia, Fonoaudiologia e Terapia Ocupacional da FMUSP.

${ }^{2}$ Terapeuta Ocupacional, aluna do Programa de Pós-Graduação em Ciências da Reabilitação da FMUSP.

Endereço para correspondência: Departamento de Fisioterapia, Fonoaudiologia e Terapia Ocupacional da FMUSP. Rua Cipotânea, 51, Cidade Universitária, São Paulo, SP, CEP: 05360-160.
} 


\section{INTRODUÇÃO}

A população que sofre de algum transtorno mental é reconhecida como uma das mais excluídas socialmente. Estudos demonstram que tal população é quatro vezes mais propensa que a média a não ter um amigo próximo e que mais de um terço afirma não ter ninguém a quem recorrer num momento de crise (OMS, 2001; HUXLEY; THORNICROFT, 2003). As pessoas com transtornos deste tipo apresentam redes sociais menores do que a média das outras pessoas, de acordo com estudos específicos sobre redes sociais e saúde mental. No caso da esquizofrenia, os sujeitos com esse tipo de diagnóstico possuem a rede social reduzida a $1 / 3$ do tamanho estimado da rede de indivíduos que não apresentam transtornos dessa natureza (STARACE; GRITTI, 1987).

Por outro lado, diversos autores apresentam dados que demonstram que a pessoa que sofre de algum transtorno mental severo e persistente, quando inserida em redes fortes de troca e suporte, apresentam maior probabilidade de êxito positivos no tratamento, em breves períodos de tempo, nas áreas clinica, laborativa e social. A associação entre rede social e êxito no tratamento em saúde mental é forte e persistente e independe de outros fatores prognósticos (LEFF; TRIEMAN, 2000; BECKER et al., 1997; BEDONI, 1995; CASTELFRANCHI, 1995, 1998, 2003, 2004; HALL; NELSON, 1996; DAYSON et al., 1998; MERCIER et al., 1998; SARACENO, 1998, 1999; HOWARD et al., 2000; BENGTOSSON-TOPS; HANSSON, 2003; TERZIAN, TOGNONI, 2003).

Ciompi (1994) afirma que, nos momentos de crise, quanto maior for o apoio social recebido pelo individuo, menor será a necessidade de contenção ou sedação. Afirma também que as expectativas depositadas pelo ambiente externo neste individuo, quando positivas, podem configurar-se no reforço mais potente para o tratamento.

A partir destes dados, autores defendem que investimentos devem ser realizados pelos serviços de atenção em saúde mental, no sentido de fortalecer e estimular a inserção em redes de trocas e a inclusão social, transformando tais ações em metas para o tratamento em saúde mental e para a construção de políticas publicas neste setor (HUXLEY; THORNICROFT, 2003).

\section{Apresentação do estudo}

Nesta perspectiva, apresentamos dados parciais da pesquisa de mestrado intitulada " $A$ sustentabilidade $d a$ vida cotidiana. Um estudo das redes sociais de usuários de um serviço de saúde mental no município de Santo
André.", desenvolvida no Programa de Pós-Graduação em Ciências da Reabilitação, da Faculdade de Medicina da USP.

A pesquisa está sendo realizada no município de Santo André e teve inicio em 2005. Desenvolve-se no contexto da parceria firmada entre o curso de Terapia Ocupacional da USP e a Secretaria de Saúde do município, que tem como resultado a realização da pesquisa "Estudo Colaborativo sobre a experiência da rede de serviços em saúde mental do município de Santo André - SP: caracterizando os serviços, conhecendo resultados e desenvolvendo um experimento sobre ativação de rede social".

O objetivo geral proposto pela presente pesquisa é caracterizar as redes sociais de pessoas com transtornos mentais severos, usuários de serviços substitutivos de saúde mental e identificar fatores que contribuam para a formulação de estratégias de ativação de redes sociais.

A pesquisa se inscreve no campo da investigação qualitativa, se utiliza de procedimentos orientados pela etnometodologia e pretende apreender a complexidade do fenômeno estudado, alem de trazer contribuições para o debate contemporâneo acerca do tema.

A coleta, realizada pela lógica da triangulação de métodos, combinou diferentes técnicas orientadas pela postura etnográfica, buscando-se assim maior abrangência na abordagem dos dados. $\mathrm{O}$ enfoque maior foi dado à observação participante, ao reconhecimento de itinerários terapêuticos e à interação com os sujeitos da pesquisa no contexto do processo assistencial (MINAYO et al., 2005; ALVES; SOUZA, 1999).

As informações foram extraídas a partir da realização de entrevista por pauta aplicada aos usuários, do processo de observação participante e da elaboração de caderno de campo, cujo objetivo foi o de captar informações e percepções sobre o cotidiano dos usuários no contexto da assistência prestada pelo serviço.

Foram realizadas 25 entrevistas com usuários pertencentes a um grupo caracterizado por apresentar transtornos mentais severos e persistentes e receber, à época da coleta, regime de tratamento intensivo no Núcleo de Atenção Psicossocial II (NAPS II). As entrevistas aconteceram no período de fevereiro e março de 2006, no contexto desse serviço de atenção, buscando-se respeitar o cotidiano e as dinâmicas próprias dos usuários no percurso de seu acompanhamento; foram gravadas e posteriormente transcritas.

A análise preliminar dos dados possibilitou a caracterização das redes sociais de usuários entrevistados; a caracterização e discussão das relações vivenciadas pelos usuários e suas necessidades, e a discussão e reflexão sobre o papel das redes sociais no percurso assistencial.

O processo de análise de conteúdo combinou as 
MÂnGiA, E. F.; MURAmoto, M. Redes sociais e construção. Rev. Ter. Ocup. Univ. São Paulo, v. 18, n. 2, p. 54-62, maio/ago., 2007.

estratégias propostas pela análise de enunciação e pela análise temática (MINAYO, 1992). Dessa forma, a partir dos procedimentos iniciais de transcrição, leitura minuciosa e pareamento de conteúdo, de acordo com os objetivos propostos, foram estabelecidas as temáticas de análise que combinaram os objetivos da investigação aos conteúdos expressos pelos entrevistados. Para cada categoria escolhida foi elaborado um texto analítico contemplando as seguintes séries discursivas: a) os conteúdos explícitos; d) as diferentes posições dos atores; c) o texto analítico propriamente dito cotejando a comparação sobre as diferenças encontradas e o referencial teórico adotado pela pesquisa (MÂNGIA, 2006).

Quanto ao material coletado por meio do diário de campo, foram seguidos os mesmos passos metodológicos e o material resultante também foi utilizado para: elaborar os tópicos de apresentação e discussão dos contextos estudados; compondo assim um campo dialógico que busca promover a interação entre a experiência do pesquisador e a construção de seu ponto de vista e os diferentes pontos de vista dos entrevistados e sustentar as conclusões preliminares do estudo em correlação com o referencial teórico assumido (MÂNGIA, 2006).

\section{Apresentação dos dados}

Com a intenção de refletir sobre o papel das redes sociais no percurso assistencial dos usuários, ou mais precisamente, na construção de seus itinerários terapêuticos, apresentamos dados sobre o tamanho da rede pessoal do grupo entrevistado.

\section{Quadro de caracterização dos usuários}

Primeiramente, apresentamos no Quadro 1 dados que permitem visualizar a caracterização dos usuários entrevistados; estes dizem respeito ao sexo, idade, hipótese diagnóstica, núcleo habitacional, situação de trabalho, rendimento/benefício, tempo de transtorno e tempo de tratamento no NAPS (Quadro 1).

Quadro 1 - Caracterização dos usuários.

\begin{tabular}{|c|c|c|c|c|c|c|c|c|}
\hline Usuário & Sexo & Idade & Hipótese diagnóstica & $\begin{array}{c}\text { Núcleo } \\
\text { habitacional }\end{array}$ & $\begin{array}{c}\text { Situação } \\
\text { de } \\
\text { trabalho }\end{array}$ & $\begin{array}{l}\text { Rendimento } \\
\text { /benefício }\end{array}$ & $\begin{array}{c}\text { Tempo de } \\
\text { transtorno }\end{array}$ & $\begin{array}{l}\text { Tempo no } \\
\text { NAPS }\end{array}$ \\
\hline A.P. & $\mathrm{M}$ & 46 & F 20 - esquizofrenia & Família & Não & Nenhum & $>20$ anos & $1-5$ anos \\
\hline A.A.O. & $\mathrm{M}$ & 38 & $\begin{array}{l}\text { F } 31 \text { - transtorno afetivo } \\
\text { bipolar }\end{array}$ & Família & Ativo & Trabalho & $>20$ anos & $1-5$ anos \\
\hline A.S.A. & M & 36 & F 20-esquizofrenia & Família & Afastado & Auxílio-doença & $>10$ anos & $<1$ ano \\
\hline A.S.S. & $\mathrm{F}$ & 24 & F 20-esquizofrenia & Família & Não & Nenhum & $>10$ anos & $<1$ ano \\
\hline A.S.D. & M & 24 & $\begin{array}{l}\text { F } 06 / \text { F } 79 \text { - o.t.m.o.*/def. } \\
\text { mental }\end{array}$ & Família & Não & Nenhum & $>20$ anos & $5-10$ anos \\
\hline A.S. & $\mathrm{M}$ & 32 & $\begin{array}{l}\text { F } 31-\text { transtorno afetivo } \\
\text { bipolar }\end{array}$ & Família & Afastado & Auxílio-doença & $1-5$ anos & $1-5$ anos \\
\hline A.H.O. & $\mathrm{F}$ & 34 & F 20 - esquizofrenia & Família & Afastado & Auxílio-doença & $5-10$ anos & $1-5$ anos \\
\hline A.M.M. & $\mathrm{F}$ & 44 & F 20- esquizofrenia & Família & Não & Aposentadoria & $>20$ anos & $5-10$ anos \\
\hline A.A. & M & 52 & F 20 - esquizofrenia & Família & Não & Aposentadoria & $>20$ anos & $>10$ anos \\
\hline C.L.V. & $\mathrm{F}$ & 66 & F 20-esquizofrenia & Sozinho & Não & Aposentadoria & $>20$ anos & $1-5$ anos \\
\hline D.P. & M & 37 & $\begin{array}{l}\text { F 06/ F } 20- \\
\text { o.t.m.o.*/esquizofrenia }\end{array}$ & Família & Não & Aposentadoria & $>20$ anos & $5-10$ anos \\
\hline G.R.F. & $\mathrm{F}$ & 30 & $\begin{array}{l}\text { F } 31 \text { - transtorno afetivo } \\
\text { bipolar }\end{array}$ & Família & Afastado & Nenhum & $1-5$ anos & $1-5$ anos \\
\hline I.F. & $\mathrm{F}$ & 56 & F 20-esquizofrenia & Residência & Não & Aposentadoria & $>20$ anos & $5-10$ anos \\
\hline J.R.N. & M & 42 & $\begin{array}{l}\text { F } 31 \text { - transtorno afetivo } \\
\text { bipolar }\end{array}$ & Residência & Não & Aposentadoria & $>20$ anos & $5-10$ anos \\
\hline J.T. & $\mathrm{M}$ & 55 & $\begin{array}{l}\text { F } 32.3 \text { - episódios } \\
\text { depressivos }\end{array}$ & Família & Afastado & Auxílio-doença & $1-5$ anos & $1-5$ anos \\
\hline M.E.A. & $\mathrm{F}$ & 45 & $\begin{array}{l}\text { F 06/ F } 31 \text { o.t.m.o.*/ } \\
\text { transt. afetivo bipolar }\end{array}$ & Família & Não & $\begin{array}{l}\text { Aposentadoria } \\
\text { do marido }\end{array}$ & $>20$ anos & $>10$ anos \\
\hline N.M.S. & $\mathrm{M}$ & 36 & F 20 - esquizofrenia & Família & Não & Nenhum & $10-20$ anos & $5-10$ anos \\
\hline N.B. & $\mathrm{M}$ & 62 & F 20 - esquizofrenia & Abrigo & Não & Aposentadoria & $>20$ anos & $1-5$ anos \\
\hline Q.I.N. & $\mathrm{F}$ & 33 & $\begin{array}{l}\text { F } 32 \text { - episódios } \\
\text { depressivos }\end{array}$ & Família & Ativo & Trabalho & $5-10$ anos & $<1$ ano \\
\hline R.B.S. & $\mathrm{F}$ & 32 & F 20 - esquizofrenia & Família & Não & Nenhum & $>20$ anos & $>10$ anos \\
\hline R.O. & $\mathrm{M}$ & & F 20 - esquizofrenia & Família & Afastado & Auxílio-doença & $1-5$ anos & $1-5$ anos \\
\hline V.L.S. & $\mathrm{F}$ & 38 & F 20 - esquizofrenia & Família & Ativo & $\begin{array}{l}\text { Benefício - } \\
\text { LOAS }\end{array}$ & $5-10$ anos & $1-5$ anos \\
\hline V.T.L. & M & 42 & F 20 - esquizofrenia & Família & Não & Aposentadoria & $10-20$ anos & $5-10$ anos \\
\hline W.L.S.S. & $\mathrm{M}$ & 29 & $\begin{array}{l}\text { F } 31 \text { - transtorno afetivo } \\
\text { bipolar }\end{array}$ & Família & Ativo & Trabalho & $5-10$ anos & $1-5$ anos \\
\hline W.C.G.N. & $\mathrm{M}$ & 28 & F 20 - esquizofrenia & Família & Não & Aposentadoria & $10-20$ anos & $1-5$ anos \\
\hline
\end{tabular}

(*) outros transtornos mentais orgânicos 
MÂngia, E. F.; MURAmoto, M. Redes sociais e construção. Rev. Ter. Ocup. Univ. São Paulo, v. 18, n. 2, p. 54-62, maio/ago., 2007.

A partir dessas informações é possível identificar características que podem contribuir para a compreensão e caracterização desse grupo e para a identificação de aspectos comuns que permitam a construção de seu perfil geral.

\section{Redes sociais}

Aqui, apresentamos dados coletados sobre o tamanho das redes sociais dos usuários entrevistados, além da caracterização dos componentes considerados nessa mensuração.

O objeto rede social tem sido utilizado em estudos de diversas áreas do conhecimento. Sua operatividade reside no fato de que ele permite apreender a complexidade das relações sociais e compreender a realidade social, indo de encontro aos limites presentes em dicotomias do tipo individuo e sociedade, ação e estrutura, objetividade e subjetividade, tradicionais nos estudos sociológicos. Estas acabam por limitar a compreensão do real e não são capazes de apreender os processos complexos das interações sociais (MARTELETO, 2001; MARTINS; FONTES, 2004; MOLINA, 2005).

Buscar conhecer e explicar aspectos da vida social a partir do referencial das redes sociais pode contribuir para a superação das reduções operadas pelos modelos explicativos tradicionais que, para conhecer, dividem um objeto complexo em partes que tendem a perder a conexão com o todo. Esse tipo de racionalidade representa a realidade social de maneira estática, não sendo capaz de captar os constantes processos de transformação e mudanças sociais (MOLINA, 2005).

Nesse sentido, as redes sociais ocupam um lugar estratégico na reflexão sobre a construção/invenção de novos modelos de pesquisa capazes de apreender as dinâmicas complexas presentes nos processos de interações sociais que estruturam a sociabilidade. $\mathrm{O}$ referencial das redes sociais responde a exigência contemporânea de complexificação da teoria social e pode ser útil tanto para a análise de fenômenos mais específicos e locais como para a análise de fenômenos globais (MOLINA, 2005).

Estudos em diferentes áreas do conhecimento reconhecem que as redes sociais se constituem como espaço potencial de trocas materiais e afetivas, no qual as pessoas encontram suporte e apoio social, compartilham problemas e tentam encontrar soluções em conjunto, além de trocarem informações (MARTINS; FONTES, 2004; MOLINA, 2005).

Para o campo da saúde mental, e especialmente para configuração de itinerários terapêuticos de pessoas com transtornos mentais severos, as redes sociais se configuram no contexto de espaços complexos de interações que podem oferecer apoio em momentos críticos e suportes significativos para a produção e reprodução da vida social, protegendo assim os grupos vulneráveis contra os riscos dos processos de desfiliação (CASTEL, 2000; SOUZA, 1999).

Neste sentido, a compreensão sobre como as pessoas se inserem nos diversos espaços que compõem a sua vida e a maneira pela qual interagem e vivenciam suas relações se mostra importante, na medida em que tal conhecimento torna possível identificar fatores que atuam enquanto protetores e aqueles que representam riscos, pois um mesmo contexto social pode produzir, de acordo com o circuito de relações experimentada pela pessoa, processos positivos de inclusão e promoção da saúde ou processos mais negativos que vulnerabilizam e podem levar á institucionalização e ao abandono. Sobre essas configurações mutáveis e contingentes devem interferir os serviços de saúde mental.

Estudos sobre estimação do tamanho da rede social de pessoas comuns mostram que, em media, a rede pessoal de um sujeito consiste em aproximadamente 290 contatos ativos, com desvios que variam de acordo com a posição social da pessoa. Já os estudos que buscam identificar a quantidade de pessoas com as quais um indivíduo mantém contatos ao longo da vida estimam que seja entre 1500 e 3500 pessoas. Por outro lado, os resultados sobre a presença de laços fortes indicam uma média de 18,5 pessoas. Esses laços fortes geralmente são representados pelo núcleo familiar mais próximo e alguns amigos e vizinhos, pessoas com quem o contato é ativo e recíproco. São as pessoas com quem se pode contar no dia-a-dia (MOLINA, 2005).

Tendo em vista esses dados, apresentamos, no Quadro 2, dados sobre o número de pessoas nomeadas pelos entrevistados, nas esferas consideradas como componentes da rede social, de acordo com a teoria sobre os estudos de rede. É importante explicitar que foi solicitado aos entrevistados que nomeassem as pessoas com quem mais tem contato, com quem mais conversam e/ou recorrem nas diversas situações do cotidiano.

As esferas consideradas para compor a rede social dos entrevistados foram: núcleo habitacional/família, família expandida, amigos e vizinhos, trabalho e relações vivenciadas a partir da inserção no serviço de atenção.

Os estudos de redes consideram que a rede social de uma pessoa apresenta um núcleo denso, formado pelas pessoas mais próximas, como núcleo familiar, amigos e vizinhos, e uma periferia expandida, na qual estão as relações vivenciadas no trabalho, com os parentes e outros familiares e pessoas conhecidas, mas não muito próximas. 
MÂngia, E. F.; MURAmoto, M. Redes sociais e construção. Rev. Ter. Ocup. Univ. São Paulo, v. 18, n. 2, p. 54-62, maio/ago., 2007.

Quadro 2 - Quantidade de pessoas nomeadas.

\begin{tabular}{|c|c|c|c|c|c|c|}
\hline Nome & $\begin{array}{c}\text { Núcleo } \\
\text { habitacional/ } \\
\text { Família } \\
\end{array}$ & $\begin{array}{c}\text { Família } \\
\text { expandida }\end{array}$ & $\begin{array}{l}\text { Amigos e } \\
\text { vizinhos }\end{array}$ & Trabalho & $\begin{array}{c}\text { Relações } \\
\text { vivenciadas no } \\
\text { serviço } \\
\end{array}$ & $\begin{array}{l}\text { Total de pessoas } \\
\text { referidas }\end{array}$ \\
\hline A.P. & 1 & 2 & 5 & 0 & 3 & 11 \\
\hline A.A.O. & 5 & 3 & 4 & 2 & 5 & 19 \\
\hline A.S.A. & 7 & 2 & 3 & 0 & 4 & 16 \\
\hline A.S.S. & 2 & 1 & 4 & 0 & 1 & 8 \\
\hline A.S.D. & 3 & 4 & 0 & 0 & 3 & 10 \\
\hline A.S. & 1 & 6 & 2 & 0 & 7 & 16 \\
\hline A.H.O. & 5 & -- & 2 & 0 & 7 & 14 \\
\hline A.M.M. & 3 & 1 & 2 & 0 & 2 & 8 \\
\hline A.A. & 2 & 7 & 4 & 0 & 4 & 17 \\
\hline C.L.V. & 0 & 3 & 2 & 0 & 2 & 7 \\
\hline D.P. & 1 & 3 & 0 & 0 & 1 & 5 \\
\hline G.R.F. & 1 & 2 & 12 & 0 & 4 & 19 \\
\hline I.F. & 9 & 4 & 0 & 0 & 1 & 14 \\
\hline J.R.N. & 9 & 5 & 4 & 0 & 3 & 21 \\
\hline J.T. & 1 & 5 & 3 & 0 & 4 & 13 \\
\hline M.E.A. & 2 & 6 & 4 & 0 & 12 & 24 \\
\hline N.M.S. & 2 & 2 & 1 & 0 & 3 & 8 \\
\hline N.B. & 9 & 2 & 1 & 0 & 2 & 14 \\
\hline Q.I.N. & 2 & 4 & 1 & 1 & 4 & 12 \\
\hline R.B.S. & 6 & 1 & 0 & 0 & 0 & 7 \\
\hline R.O. & 1 & 1 & 0 & 0 & 0 & 2 \\
\hline V.L.S. & 8 & -- & 5 & 0 & 3 & 16 \\
\hline V.T.L. & 4 & 2 & 0 & 0 & 2 & 8 \\
\hline W.L.S.S. & 2 & -- & 1 & 0 & 7 & 10 \\
\hline W.C.G.N. & 2 & 5 & 0 & 0 & 4 & 12 \\
\hline
\end{tabular}

Neste estudo, as relações vivenciadas a partir da inserção no serviço também foram consideradas e, a princípio, localizadas no grupo cujas relações são menos intensas, ou seja, na periferia expandida (MOLINA, 2005).

O núcleo habitacional/família é composto por aquelas pessoas que moram com os usuários. Conforme já mencionado, de acordo com os estudos em rede social, é o grupo que compõe o núcleo denso de relações do sujeito.

A família expandida caracteriza-se pelos familiares que não compõem o núcleo habitacional da pessoa. Estudos sobre redes sociais e saúde mental estimam que a rede social de um sujeito com transtorno mental severo seja composta por $70 \%$ de familiares. A estimativa para a população comum é de $50 \%$. De acordo com os números apresentados no Quadro 2, é possível verificar que apenas 5 usuários apresentam essa proporção. A maioria dos entrevistados tem as relações vivenciadas a partir da inserção no serviço como maior proporção da formação da rede social (MOLINA, 2005, HUXLEY; THORNICROFT, 2003).

Para a nomeação das pessoas na esfera amigos e vizinhos, solicitamos aos usuários que desconsiderassem as relações surgidas a partir de laços familiares e a partir da inserção no serviço de assistência. Esta é uma esfera considerada por alguns autores como também componente do núcleo denso de relações do sujeito. Os estudos de redes em comunidades mostram que os vizinhos ganham importância, especialmente devido à proximidade do cotidiano vivenciado, o que permite que diversas questões sejam compartilhadas, informações trocadas e que a possibilidade de encontram apoio e suporte mútuos seja ampliada. Estudos mais específicos apontam que, em 
muitos casos, os vizinhos são os primeiros a serem solicitados em situações de emergências. É possível observar que a participação dos usuários nessas redes promove um importante grau de proteção, tanto para situações comuns vivenciadas no cotidiano, quanto para aquelas que demandam mais atenção e cuidado. A percepção dessas relações de ajuda também se mostra como dado importante para a compreensão dos processos de busca e obtenção de apoios pessoais e sociais (MOLINA, 2005, HUXLEY; THORNICROFT, 2003).

Os laços existentes a partir da inserção em alguma atividade laborativa são considerados importantes pela literatura de redes, uma vez que, na fase adulta, configuram grande parte das relações vivenciadas pelas pessoas (MOLINA, 2005). Entre os entrevistados, apenas quatro usuários encontram-se em situação ativa de trabalho. Dentre esses, apenas dois mencionaram relações consideradas importantes nesta esfera.

A ultima esfera considerada foi a composta por relações vivenciadas a partir da inserção no serviço de assistência. Aqui, os usuários identificaram os laços que possuem com as pessoas pertencentes ao contexto do NAPS: técnicos, funcionários e outros usuários.

\section{Redes sociais e itinerários terapêuticos}

Foi possível observar, nos diversos relatos coletados e nos contextos analisados no processo de observação participante, que muitos usuários acabam por perder espaços na casa e na família, conforme as trajetórias vividas em diversos momentos de ruptura ocasionadas, especialmente nos momentos de crise ou imediatamente após as situações de crise. Nesses períodos ocorre a diminuição da presença e participação dos usuários na rotina da casa, pelo aumento do período de permanência no serviço, ou pela ocorrência de um período de internação, mesmo que breve. Ao regressarem á rotina habitual, muitos encontram os espaços domésticos ou familiares cada vez mais reduzidos, tanto no plano concreto, como por exemplo, ter preservado o quarto, ou a cama onde dormia, o armário onde colocava suas roupas, etc, quanto no plano afetivo e simbólico, configurado nos momentos de trocas familiares, conversas, validação de sua opinião perante o grupo, convites para visitar parentes ou amigos, participar das festas familiares, dentre outros.
Também com relação aos laços vivenciados fora do âmbito familiar, os relatos e a observação nos mostram que os sujeitos tendem a perder as relações de amizade; estas vão sendo enfraquecidas na medida em que os processos de ruptura e vulnerabilização das pessoas se reproduzem e não encontram o suporte necessário por parte do serviço de atenção e da família.

A eclosão de um transtorno mental em um determinado contexto sócio familiar cria uma situação crítica que mobiliza todos os atores no processo de busca de soluções, tanto dirigidos ao sujeito que sofre, como ao próprio grupo do qual ele faz parte. Nesse processo, a própria identificação do problema se configura no contexto das relações e a partir da percepção das alterações produzidas pelos transtornos mentais nas interações sócio-relacionais que compõem o cotidiano, desencadeadas especialmente pelo comportamento diferente do sujeito em crise. Assim, o transtorno mental é um problema, ao mesmo tempo, individual e coletivo, ou seja, um fenômeno que envolve a rede social (MÂNGIA, 2006).

As redes sociais têm um papel na identificação do problema e também na busca de solução e escolhas terapêuticas. Nesse processo, se percebe também rearranjos, rupturas, dissolução e reconfiguração das redes sociais, pois sabemos que as situações decorrentes dos transtornos mentais, especialmente aqueles severos e persistentes podem trazer mudanças significativas nas trajetórias de vida da pessoa e em seu circuito relacional (SOUZA, 1999; MÂNGIA, 2006).

Souza destaca que, no geral, os estudos tradicionais não levam em conta os percursos das pessoas, do momento que identificam a enfermidade até a obtenção das formas de ajuda. Ressalta também que esses percursos são heterogêneos embora quase sempre levem a alguma ajuda técnica, ou a entrada em um serviço de saúde, além disso, a própria identificação e definição do problema sofre modificações ao longo do tempo e está em permanente interação com o contexto no qual se processa a busca de ajuda ou suporte (SOUZA, 1999).

"A atribuição a alguém de um papel de doente ou do rótulo de louco, emerge de um processo interativo que envolve a participação de vários atores pertencentes às redes sociais (...) Ressalta-se que as redes sociais possuem uma dimensão que induz e constrange o comportamento dos indivíduos, levando-os a tomar certas decisões e possui também um papel produtivo e construtivo, pois ser doente não é apenas uma condição biológica ou psicologicamente dada, mas 
um produto constituído com base nas definições e reações dos outros" (SOUZA, 1999, p.121).

O estudo sobre itinerários terapêuticos parte da constatação sobre a multiplicidade das formas de enfrentamento dos problemas de saúde presentes na atualidade e busca compreender como as pessoas e os grupos sociais realizam escolhas e aderem aos tratamentos. (ALVES; SOUZA, 1999, p. 125).

A compreensão sobre os itinerários terapêuticos deve levar em conta os diferentes contextos de vida que definem as possibilidades de oferta e acesso aos serviços de saúde, no geral, nas grandes cidades essa oferta aparece mais ampliada e definida pela rede de serviços de saúde, encontramos também nesse campo a diversidade de interpretações e métodos terapêuticos dificilmente compreendidos pela população em geral. Além desses aspectos, as opções e decisões sobre os tratamentos de saúde sofrem influência do contexto sócio econômico e o próprio acesso á informação está relacionado a contratualidade do sujeito e seu lugar no campo das trocas sociais.

Alves assinala que a análise dos itinerários terapêuticos foi muito influenciada pelos estudos sobre redes sociais. Como o conceito de "management group of therapy", proposto por Janzen, " que consiste em um grupo de parentes e amigos mobilizados para definir a situação e buscar soluções diante do adoecimento de um indivíduo". Esse grupo troca informações, prove apoio, toma decisões e providências (JANZEN apud ALVES; SOUZA, 1999, p. 128).

Alves e Souza criticam a abordagem adotada pela maior parte dos estudos sobre itinerários terapêuticos, pois consideram que exista uma redução do trabalho interpretativo que se evidencia no caráter essencialmente explicativo de tais estudos, que adotam premissas previamente estabelecida, (tais como escolha racional, valores culturais e estruturas de redes sociais) para explicar as ações de pessoas ou grupos (ALVES; SOUZA, 1999, p. 130).

Esses autores elaboram importantes precauções teórico-metodológicas e sugerem que os estudos sobre itinerários terapêuticos devem priorizar a aproximação em relação ao conhecimento dos procedimentos utilizados pelos atores para interpretarem suas experiências e decidirem sobre suas ações. As escolhas sobre as formas de tratamento são o resultado de múltiplas negociações realizadas no contexto relacional dos sujeitos e dessa forma expressam sínteses parciais que emergem de um campo de possibilidades histórica e culturalmente definidas. O sujeito dessas ações compartilha um conjunto de "crenças e receitas práticas para lidar com o mundo" e o trabalho interpretativo do pesquisador encontra dimensões subjetivas dificilmente compreensíveis, pois esse universo compartilhado não determinam as ações de forma homogênea (ALVES; SOUZA, 1999, p. 132-33).

\section{CONSIDERAÇÕES FINAIS}

A utilização do referencial proposto nos estudos das redes sociais pode trazer contribuições importantes para o estudo dos serviços de saúde mental e das estratégias utilizadas no contexto dos projetos de reabilitação psicossocial (MARTINS; FONTES, 2004; MARTELETO, 2001).

A compreensão dos projetos terapêuticos e da problemática das populações vulneráveis no contexto de suas redes relacionais permite observar, na dinâmica das relações, os componentes que podem contribuir para a melhoria da saúde e da qualidade de vida, e, portanto, se constituem enquanto fatores de proteção e aqueles que, ao contrário, representam fatores de risco.

A participação em tais relações e intercâmbios sociais ou a sua invenção é possível no cenário das redes sociais, este enquanto lugar complexo de interações, onde os diversos graus de contratualidade e as diferentes identidades podem ser trocados. O empobrecimento da rede social também se configura como desabilitação, perda quantitativa e qualitativa, desde a primeira rede social disponível, que é o núcleo familiar, até as formas mais ampliadas de relações.

Assim, intervenções que visem integração com o núcleo familiar e a rede social ampliada da pessoa com transtorno mental severo, podem trazem benefícios tanto para as pessoas como para a qualificação dos programas de reabilitação (SARACENO, 1999, 2001; ROTELLI, 1993).

Tal tarefa exige mudanças nas culturas técnica e de organização de serviços, uma vez que demandam novos desenhos assistenciais e formativos capazes de tomarem como central não mais a remissão de sintomas e o treino de habilidades específicas, presentes na tradição da reabilitação no campo assistencial em saúde mental, mas a complexificação dos processos de intervenção, incorporando em suas estratégias o manejo dos fatores de proteção, que garantem aos sujeitos a possibilidades de viver a vida fora dos circuitos de institucionalização. 
MÂNGIA, E. F.; MURAmOto, M. Redes sociais e construção. Rev. Ter. Ocup. Univ. São Paulo, v. 18, n. 2, p. 54-62, maio/ago., 2007.

MÂNGIA, E. F.; MURAMOTO, M. Social networks and the construction of therapeutic projects: a study in a mental health substitutive service. Rev. Ter. Ocup. Univ. São Paulo, v. 18, n. 2, p. 54-62, maio/ago., 2007.

\begin{abstract}
Studies show that people with severe mental diseases who have social network present bigger probability of positive outcome in short or soon periods, in the clinic, labor and relational areas. These results should orient the elaboration and realization of assistance interventions and psychosocial rehabilitation developed by the mental health services, in a way in that the intervention about social network will be prioritized. In this perspective, we present the partial results of de master's research "The sustainability of quotidian life. A study about the social networks of users in a mental health service in the city of Santo André", started in December, 2005. The general objective is to characterize the social networks of people with mental health problems, users of mental health substitutive services and to identify factors that contribute to the formulation of activation strategies of networks. The research is located on the qualitative enquiry field and uses procedures oriented by ethnometodology. It had been done 25 interviews with users who received attention in intensive treatment regime, bibliographical research and participative observation, plus the elaboration of a field notebook. The preliminary data analysis allowed the characterization of the users social networks and their needs and also the confirmation about the importance of the social networks in the assistance's trajectory. To the assistance model, the validation of activation strategies of social networks demands changes in the technical and services organization culture, and the definition of a new assistance structure, more complex and that includes in their strategies the operation of protection factors, that assurance to the individuals the possibilities to live their lives out of the institutionalization circuits.
\end{abstract}

KEYWORDS: mental disorders. Rehabilitation. Mental health services. Institutionalization. Occupational therapy.

\title{
REFERÊNCIAS
}

ALVES, P. C. B.; SOUZA, I. M. Escolha e avaliação de tratamento para problemas de saúde: considerações sobre o itinerário terapêutico. In: RABELO, M. C. M.; ALVES, P. C. B.; SOUZA, I. M. A. Experiência de doença e narrativa. Rio de Janeiro: Fiocruz, 1999. [Coleção Antropológica e Saúde].

BECKER, T.; THORNICROFT, G.; LEESE, M.; McCRONE, P.; JOHNSON, S.; ALBERT, M.; TURNER, D. Social networks and service use among representative cases of psychosis in South London. Br. J. Psychiatry, v. 171, n. 7, p.15-9, 1997.

BEDONI, A. Um commento agli studi prospettici sull’esito dei disturbi schizofrenici pubblicati negli ultimo 10 anni. Lettera Percorsi Bibliografici in Psichiatria, Istituto di Ricerche Farmacologiche "Mario Negri”, Milano, v. 20, p. 96-145, 1995.

BENGTSSON-TOPS, A.; HANSSON, L. Clinical and social changes in severely mentally ill individuals admitted to an outpatient psychosis team: an 18-month follow-up study. Scand. J. Caring. Sci., v. 17, p. 3-11, 2003.

CASTEL, R. As armadilhas da exclusão. In: CASTEL, R.; WANDERLEY, L.E.N.; BELFIORE, W.M. Desigualdade e a questão social. São Paulo: Educ, 2000.
CASTELFRANCHI, C.; HENRY, P.; PIRELLA, A. L'invenzione colletiva. Torino: Edizioni Gruppo Abele, 1995.

CASTELFRANCHI, C. Prevenzione. Tra pessimismo della ragione e ottimismo della volontà. In: PICCIONE, R. ( $a$ cura di) Prevenzione e salute mentale. Fondamenti, pratiche, prospecttive. Roma: Carocci Editore, 1998

CASTELFRANCHI, C. La produzione interpersonale ed istituzionale della gravità. In: ATTENASIO, L. (a cura di) Dialogo con la follia. Un approccio colletivo al trattamento del paziente grave. Roma: Armando Editore, 2003.

CASTELFRANCHI, C. Rete di supporto sociale ed intervento sui processi psichici. Matera, nov. 2004. (mimeo).

CIOMPI, L. Logica affettiva, Milano: Feltrinelli, 1994.

DAYSON, D; LEE-JONES,R; CHAHAL,K.K; LEFF,J. The TAPS Project 32: social network of two group homes ... 5 years on. Social Psychiatr. Psychiatr. Epidemiol., v. 33, p. 438-444, 1998.

HALL, G. B.; NELSON, G. Social networks, social support, personal empowerment, and the adaptation of psychiatric 
MÂngia, E. F.; MURAmoto, M. Redes sociais e construção. Rev. Ter. Ocup. Univ. São Paulo, v. 18, n. 2, p. 54-62, maio/ago., 2007.

consumers/survivors: path analytic models. Social Sci. Med., v. 43, n. 12, p. 1743-54, 1996.

HOWARD, L.; LEESE, M.; THORNICROFT, G. Social networks and functional status in patients with psychosis. Acta Psychiatr. Scand., v. 102, n. 5, p. 376-85, 2000.

HUXLEY, P.; THORNICROFT, G. Social inclusion, social quality and mental illness. Br. J. Psychiatr., v. 182, p. 289-290, 2003.

LEFF, J. ; TRIEMAN, N. Long-stay patients discharged from psychiatric hospitals. Social and clinical outcomes after five years in the community. The TAPS Project 46. Br. J. Psychiatr., v. 176, p. 217-223, 2000.

MÂNGIA, E. F. Notas metodológicas para a pesquisa de campo e análise de entrevistas. Lab. Conexões, FMUSP, 2006. 30p. (mimeo).

MARTELETO, R. M. Análise de redes sociais - aplicação nos estudos e transferência da informação. Rev. Ciên. Inf., v. 30, n. 1, p. 71-81, 2001.

MARTINS, P.; FONTES, B. Redes sociais e saúde: novas possibilidades teóricas. Recife: Editora Universitária da UFPE, 2004.

MERCIER, C.; CARON, J.; TEMPIER, R.; LEOUFFRE, P. Components of social support and quality of life in severely mentally ill, low income individuals and a general population group. Community Mental Health J., v. 34, n. 5, 1998.

MINAYO, M. C. S. O desafio do conhecimento: pesquisa qualitativa em saúde. São Paulo: Hucitec/Abrasco, 1992.
MINAYO, M. C. S.; ASSIS, S. G.; SOUZA, E. R. (Orgs.). Avaliação por triangulação de métodos. Abordagem de programa social. Rio de Janeiro: Fiocruz; 2005.

MOLINA, J. L. El estudio de las redes personales: contribuciones, métodos y perspectivas. 2005. Disponível em: http://revistaredes.rediris.es/

ORGANIZAÇÃO MUNDIAL DA SAÚDE (OMS), Organização Panamericana da Saúde (OPAS). Relatório sobre a saúde no mundo - 2001. Saúde mental: nova concepção, nova esperança. Rio de Janeiro: Gráfica Brasil, Organização Mundial da Saúde, 2001.

ROTELLI, F. Re-habilitar la re-habilitación. 1993.

SARACENO, B. A cidadania como forma de tolerância. Conferência. Rio de Janeiro, 1998.

SARACENO, B. Libertando identidades: da reabilitação psicossocial à cidadania possível. Rio de Janeiro/ Belo Horizonte: Instituto Franco Basaglia/ Te Corá, 1999.

STARACE, F.; GRITTI, P. "Socialnetwork" and "social support": experiences and prospects for intervention. Per la salute mentale/For mental health 1987 4, Trieste; Coop. "Il Posto delle Fragole".

SOUZA, I. M. Na trama da doença: uma discussão sobre redes sociais e doença mental, In: RABELO, M. C. M.; ALVES, P. C.B; SOUZA, I. M. A. Experiência de doença e narrativa. Rio de Janeiro: FIOCRUZ, 1999. [Coleção Antropologia e Saúde].

TERZIAN, E.; TOGNONI, G. Indagine sui servizi psichiatrici di diagnosi e cura. Riv. Sperimentale Freniatria, v. 128, n. 2, Suppl, 2003. 